\title{
Ionic-Liquid-Based Electroactive Polymer Composites for Muscle Tissue Engineering
}

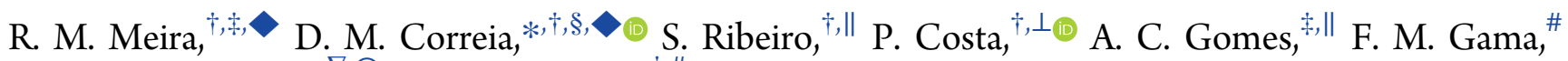
S. Lanceros-Méndez, $\nabla, \bigcirc, *$ and C. Ribeiro ${ }^{\dagger, \# \infty}$

${ }^{\dagger}$ Centre of Physics, ${ }^{\dagger}$ IB-S Institute of Science and Innovation for Sustainability, and ${ }^{\#} \mathrm{CEB}-\mathrm{Centre}$ of Biological Engineering, University of Minho, 4710-057 Braga, Portugal

${ }^{\S}$ Department of Chemistry and CQ-VR, Universidade de Trás-os-Montes e Alto Douro, 5001-801 Vila Real, Portugal

"Centre of Molecular and Environmental Biology (CBMA), University of Minho, 4710-057 Braga, Portugal

${ }^{\perp}$ Institute for Polymers and Composites (IPC), University of Minho, 4800-058 Guimarães, Portugal

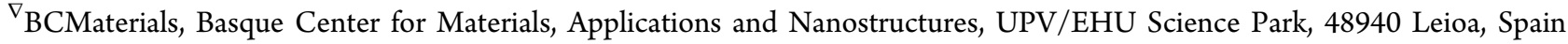

OIkerbasque, Basque Foundation for Science, 48013 Bilbao, Spain

Supporting Information

ABSTRACT: As an electromechanically active tissue, muscle regeneration takes advantage of active scaffolds providing mechanoelectrical stimuli and a biomimetic microenvironment. Thus, this study reports on the preparation of ionic electroactive materials based on ionic liquids (ILs) and poly(vinylidene fluoride) (PVDF). IL/PVDF composites with 10, 20, and 40\% wt. of 1-butyl3-methylimidazolium chloride $[\mathrm{Bmim}][\mathrm{Cl}]$ and 2-hydroxyethyl-trimethylammonium dihydrogen phosphate $[\mathrm{Ch}][\mathrm{DHP}]$ were prepared by solvent casting. It is shown that the inclusion of $[\mathrm{Bmim}][\mathrm{Cl}]$ and $[\mathrm{Ch}][\mathrm{DHP}]$ both improves the electrical conductivity and induces the PVDF crystallization in the polar $\beta$ phase. Further, the introduction of the IL also influences the thermal stability of the composites. [Bmim][Cl]/PVDF composites show larger Young moduli and a larger increase of the electrical conductivity than the $[\mathrm{Ch}][\mathrm{DHP}] / \mathrm{PVDF}$ composites. It is also shown that $[\mathrm{Bmim}][\mathrm{Cl}]$ composites show a piezoresistive response, with gauge factors from 1 to 2.5 , allowing them therefore to work as electromechanical sensors in biomechanical applications. The noncytotoxicity of the IL/PVDF composite films and $\mathrm{C} 2 \mathrm{C} 12$ cell proliferation demonstrates the applicability of the composites as a suitable platform for muscle regeneration strategies.

KEYWORDS: electroactive, ionic liquid, PVDF, smart materials, tissue engineering

\section{INTRODUCTION}

Tissue engineering (TE) is concerned with the development of biological substitutes to improve tissue functions. ${ }^{1}$ TE often combines cells, growth factors, and scaffolds. ${ }^{2}$ The scaffold needs to be biocompatible and must match the properties of the tissue to be replaced or repaired, providing a physical support for cells. ${ }^{3}$

Specific smart and/or multifunctional materials allow the natural cell environment to be mimicked by providing mechanic and/or electric stimuli resembling the stimuli in the human body. ${ }^{4}$ Indeed, many living tissues react to electromechanical solicitations, namely, muscle tissue. ${ }^{5}$ Thus, the use of electroactive materials, such as piezoelectric polymers, allows the development of an electrical response under mechanical stimuli, showing a strong application potential for tissue engineering strategies. ${ }^{4}$ In this way, electromechanically responsive polymers are a promising

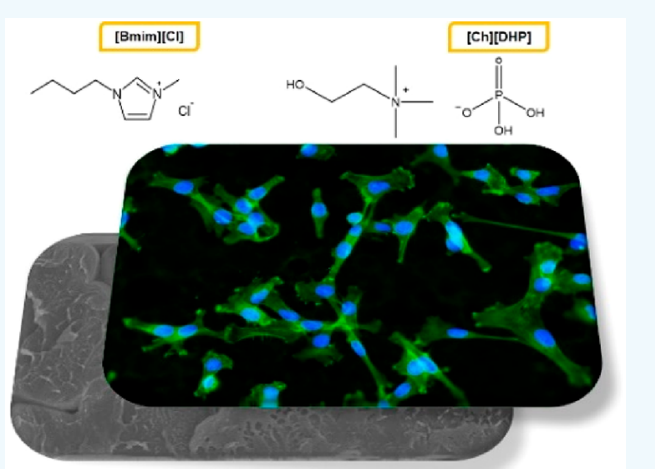

material for novel active muscle tissue engineering strategies. $^{6,7}$

Poly(vinylidene fluoride) (PVDF) is a biocompatible polymer with ferro, pyro, and piezoelectric electroactive responses, high thermal stability, mechanical strength, and chemical resistance. ${ }^{8}$ This semicrystalline polymer exhibits four distinct crystalline phases, the $\beta$-phase showing the highest piezoelectric response and consequently being the most desirable for TE applications. ${ }^{9}$ This phase is usually obtained by solvent casting (temperature $<70{ }^{\circ} \mathrm{C}$ ) or from the melt (after high temperature stretching) or through the introduction of specific fillers, including zeolites, ${ }^{10}$ ferrites, ${ }^{11}$ and ionic liquids (ILs). ${ }^{12,13}$

Received: June 19, 2019

Accepted: August 30, 2019

Published: August 30, 2019 
Ionic liquids (ILs) are organic salts with a low melting temperature, high thermal, chemical, ionic conductivity as well as electrochemical stability, and low vapor pressure. ${ }^{14,15}$ The ILs' incorporation into a polymer matrix allows the development of ionic electroactive materials, based on the existence and mobility of anions and cations of the IL. This type of IL/ PVDF composites has been explored in different applications, such as sensors, ${ }^{16}$ actuators, ${ }^{17}$ catalytic systems, ${ }^{18}$ batteries, ${ }^{19}$ and in $\mathrm{TE}^{20}$

In the TE field, few studies report the development and application of polymer-based ILs, mainly addressing the development of actuators; nevertheless, it is expected that the ionic charges from the IL promotes cell adhesion and proliferation, based on electrostatic interactions. ${ }^{4}$ Thus, it has been demonstrated that ILs modify the polymer crystallization process while increasing the electrical conductivity and plasticity of the composite materials. ${ }^{17}$ Further, the PVDF electroactive phase increases upon the incorporation of the IL into the polymer matrix. IL/PVDF actuators comprising ILs with different anions (1-hexyl-3-methylimidazolium chloride $\left[\mathrm{C}_{6} \mathrm{mim}\right][\mathrm{Cl}]$ and 1-hexyl-3-methylimidazolium bis(trifluoromethylsulfonyl)imide $\left[\mathrm{C}_{6} \mathrm{mim}\right]\left[\mathrm{NTf}_{2}\right]$ ) were developed to evaluate the anion effect in the performance of the actuator. Independently of the IL content and type, the IL induced the PVDF crystallization into the $\beta$-phase. Further, IL/PVDF composite films present a higher electrical conductivity and lower elastic modulus when compared with the pristine PVDF matrix. ${ }^{12}$

In this work, PVDF/1-butyl-3-methylimidazolium chloride $[\mathrm{Bmim}][\mathrm{Cl}]$ and PVDF/2-hydroxyethyl-trimethylammonium dihydrogen phosphate $[\mathrm{Ch}][\mathrm{DHP}]$ composite films were produced with different IL concentrations (10, 20, and $40 \mathrm{wt}$ $\%)$. Those IL were selected based on their biocompatibility and electrical conductivity. The morphological, physicochemical, including piezoresistive response, and thermal properties of the composites were analyzed, and their potential as scaffolds for muscle TE was evaluated by cytotoxicity and cell proliferation assays.

\section{EXPERIMENTAL SECTION}

2.1. Materials. Poly(vinylidene fluoride) (PVDF) (Solef 6010) was purchased from Solvay. $\mathrm{N}, \mathrm{N}$-dimethylformamide, DMF, was obtained from Merck, and the ionic liquids 2-hydroxyethyltrimethylammonium dihydrogen phosphate $([\mathrm{Ch}][\mathrm{DHP}])$ (purity higher than >98\%) and 1-butyl-3-methylimidazolium chloride $([\mathrm{Bmim}][\mathrm{Cl}])$ (purity higher than $>98 \%$ ) were supplied from Iolitec and Solvionic, respectively. The chemical structure and relevant information of both ILs are presented in Table S1, Supporting Information.

2.2. IL/PVDF Composite Film Preparation. IL/PVDF composites were prepared as described in ref 21. PVDF was dissolved in DMF $(15 / 85 \%(\mathrm{v} / \mathrm{v})$ ratio) under magnetic stirring at room temperature. Different contents $(10,20$, and $40 \%$ wt.) of both ILs $[\mathrm{Bmim}][\mathrm{Cl}]$ and $[\mathrm{Ch}][\mathrm{DHP}]$ were then added, separately. The obtained solution was spread on a glass substrate, and the solvent was evaporated in an oven (P-Selecta) at $210{ }^{\circ} \mathrm{C}$, for $10 \mathrm{~min}$, to obtain IL/PVDF films with a thickness ranging between 30 and 38 $\mu \mathrm{m}$. Figure S1, Supporting Information shows an illustration of the experimental procedure.

2.3. Sample Characterization. The samples were coated with gold (Polaron SC502 setup), and their morphology was observed by scanning electron microscopy (SEM), with a NanoSEM-Fei Nova 200 microscope at $10 \mathrm{kV}$.

Wettability measurements were performed with a Dataphysics Contact Angle System OCA20 set up at room temperature using ultrapure water $(3 \mu \mathrm{L})$ as a test liquid. Six measurements were carried out at different surface spots of each sample. The contact angle was determined using the SCA20 software and presented as the average and standard deviation.

Fourier transform infrared spectroscopy (FTIR) measurements in the attenuated total reflection (ATR) mode were conducted on a Jasco FT/IR-4100 FTIR spectrometer, between 600 and $4000 \mathrm{~cm}^{-1}$, using 64 scans and a resolution of $4 \mathrm{~cm}^{-1}$. The relative $\beta$-phase content of each sample was evaluated by applying eq 1 and the method presented in ref 8 .

$$
F(\beta)=\frac{A_{\beta}}{\left(K_{\beta} / K_{\alpha}\right) A_{\alpha}+A_{\beta}}
$$

In this equation, $F(\beta)$ represents the $\beta$-phase content, $K_{\alpha}(6.1 \times$ $\left.10^{4} \mathrm{~cm}^{2} \mathrm{~mol}^{-1}\right)$ and $K_{\beta}\left(7.7 \times 10^{4} \mathrm{~cm}^{2} \mathrm{~mol}^{-1}\right)$ are the absorption coefficients, and $A_{\alpha}$ and $A_{\beta}$ are the absorbances at 763 and $840 \mathrm{~cm}^{-1}$, respectively. ${ }^{11}$

Differential scanning calorimetry (DSC) measurements were carried out on a PerkinElmer DSC 8000 set up at a heating rate of $10{ }^{\circ} \mathrm{C} \mathrm{min}-1$ between 0 and $200{ }^{\circ} \mathrm{C}$. The degree of crystallinity $\left(\Delta X_{c}\right)$ of the composites was determined from the melting thermograms using eq $2 .{ }^{22}$

$$
\Delta X_{c}=\frac{\Delta H}{x \Delta H_{\alpha}+y \Delta H_{\beta}}
$$

In this equation, $\Delta H$ is the melting enthalpy of the sample, $\Delta H_{\alpha}$ (93.07 $\left.\mathrm{J} \mathrm{g}^{-1}\right)$ and $\Delta H_{\beta}\left(103.4 \mathrm{~J} \mathrm{~g}^{-1}\right)$ are the enthalpies of a $100 \%$ crystalline sample in the corresponding phase with $x$ and $y$ phase content, respectively. ${ }^{22}$

Thermogravimetric analysis (TGA, PerkinElmer TGA 4000) was carried out at a heating rate of $10{ }^{\circ} \mathrm{C}$ from 30 to $900{ }^{\circ} \mathrm{C} \mathrm{min}-1$ under nitrogen atmosphere in approximately $5 \mathrm{mg}$ samples sealed in $30 \mu \mathrm{L}$ aluminum pans.

The volume electrical conductivity $(\sigma)$ was evaluated from the $I-$ $V$ curves measured at a voltage range from -10 to $10 \mathrm{~V}$ with a Keithley 6487 picoammeter/voltage source. ${ }^{23}$ For the electrical measurements, parallel gold electrodes in both sides of the sample (5 $\mathrm{mm}$ diameter) were deposited with a Polaron SC502 set up.

Samples with dimensions of $14 \times 10 \mathrm{~mm}$ were analyzed by mechanical stress-strain measurements (TA.HDplus Stable Micro Systems, load cell of $50 \mathrm{~N}$ ). Three measurements were performed for each sample at a stretching rate of $1.2 \mathrm{~mm} \mathrm{~min}^{-1}$.

For the piezoresistive response, silver painted electrodes were deposited in the samples, and the electrical resistance variation (Agilent 34401A multimeter) was measured while a mechanical uniaxial deformation was applied to the samples (Shimazdu AG-IS with load cell of $50 \mathrm{~N}$ ). The silver electrodes were placed inside claws and thus did not suffer strain during the measurements. All measurements were performed at $1.2 \mathrm{~mm} \mathrm{~min}^{-1}$ in composites with 14 to $17 \mathrm{~mm}$ between clamps and $10 \mathrm{~mm}$ of width, with varying deformation from 1 to $2.5 \%$ strain. The piezoresistive response of the films was quantified by the gauge factor (GF), eq 3 .

$$
\mathrm{GF}=\frac{\mathrm{d} R / R_{0}}{\mathrm{~d} L / L_{0}}
$$

where $R_{0}$ is the initial electrical resistance, and $L_{0}$ is the initial distance between clamps.

2.4. Composite Film Sterilization. For the in vitro assays, circular samples were cut with a $13 \mathrm{~mm}$ diameter, exposed to UV light for $2 \mathrm{~h}$ ( $1 \mathrm{~h}$ each side), and washed five times in a sterile phosphate buffer saline (PBS) solution for $5 \mathrm{~min}$. The samples were then placed in a 24-well tissue culture polystyrene plate with Dulbecco's modified Eagle's medium (DMEM, Gibco) containing $4.5 \mathrm{~g} \mathrm{~L}^{-1}$ glucose (Gibco), supplemented with $10 \%$ fetal bovine serum (FBS, Biochrom) and $1 \%$ penicilin/streptomycin $(\mathrm{P} / \mathrm{S}$, Biochrom), at $37{ }^{\circ} \mathrm{C}$ in $95 \%$ humidified air containing $5 \% \mathrm{CO}_{2}$ for $24 \mathrm{~h}$. 


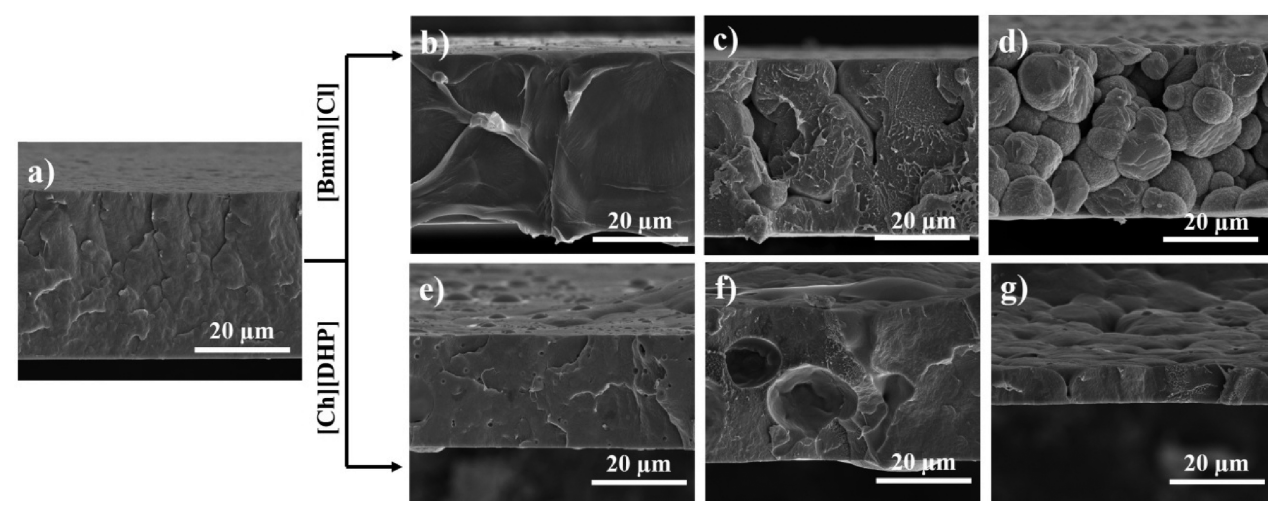

Figure 1. Cross section SEM images of (a) PVDF pristine and composite films with (b) $10 \%$ wt. [Bmim] [Cl], (c) 20\% wt. [Bmim] [Cl], (d) $40 \%$ wt. [Bmim] [Cl], (e) $10 \%$ wt. [Ch] [DHP], (f) $20 \%$ wt. [Ch][DHP], and (g) $40 \%$ wt. [Ch][DHP].
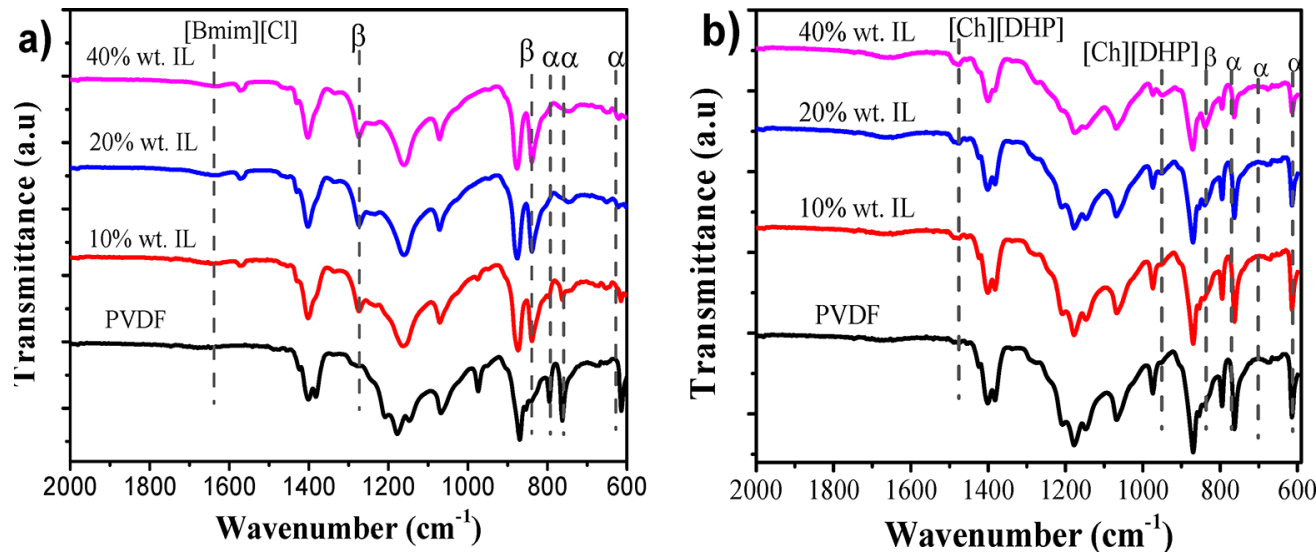

Figure 2. FTIR-ATR spectra for pristine PVDF and the composites (a) $[\mathrm{Bmim}][\mathrm{Cl}] / \mathrm{PVDF}$ and (b) [Ch][DHP]/PVDF with 10, 20, and 40\% wt. IL content.

2.5. Cell Culture. A mouse myoblast cell line ( $\mathrm{C} 2 \mathrm{C} 12$ cells) was cultivated in DMEM containing $4.5 \mathrm{~g} \mathrm{~L}^{-1}$ glucose supplemented with $10 \% \mathrm{FBS}$ and $1 \% \mathrm{P} / \mathrm{S}$ at $37{ }^{\circ} \mathrm{C}$ in $95 \%$ humidified air containing $5 \%$ $\mathrm{CO}_{2}$. C2C12 cells were collected before reaching confluence $(\sim 70 \%)$.

2.6. Cell Toxicity Assays. Indirect cell toxicity was evaluated by the quantification of the mitochondrial dehydrogenases' metabolic activity using 3-(4,5-dimethylthiazol-2-yl)-5-(3-carboxymethoxyphenyl)-2-(4-sulfophenyl)-2H-tetrazolium (MTS, Promega) assays.

For that purpose, after sterilization, the different samples were exposed to culture medium at $37{ }^{\circ} \mathrm{C}$ in $95 \%$ humidified air containing $5 \% \mathrm{CO}_{2}$ for $24 \mathrm{~h}$. In parallel, $\mathrm{C} 2 \mathrm{C} 12$ cells were cultured in 96-well plates (density of $2 \times 10^{4}$ cells $\mathrm{mL}^{-1}$ ) for $24 \mathrm{~h}$ and subsequently exposed to culture medium containing extractables resulting from prior conditioning of the culture medium with the different samples for $72 \mathrm{~h}$. The metabolic activity of the cells was assessed after $72 \mathrm{~h}$ of exposure to these extractables, by replacing the supernatant with fresh medium containing MTS solution (dilution of 1:5 in DMEM). The absorbance was measured, using a microplate reader, at $490 \mathrm{~nm}$, after $2 \mathrm{~h}$ of incubation. The positive and negative controls were, respectively, DMSO at $20 \%$ and complete cell culture medium. Four replicate measurements were performed. The cell viability was calculated according to eq 4 .

$$
\text { cell viability }(\%)=\frac{\text { absorbance of sample }}{\text { absorbance of negative control }} \times 100
$$

2.7. Cell Proliferation and Cell Morphology. $\mathrm{C} 2 \mathrm{C} 12$ cell proliferation on the different samples was evaluated after 24 and 72 h. For that, $\mathrm{C} 2 \mathrm{C} 12$ cells were placed on each sample by the drop method $(125 \mu \mathrm{L}$ of DMEM containing 7500 cells (cell density $=6 \times$ $10^{4}$ cells $\mathrm{mL}^{-1}$ ) to avoid cell seeding on the plate rather than on the material. After 24 and $72 \mathrm{~h}$, the culture medium was removed, and the samples were washed twice with PBS solution for $5 \mathrm{~min}$. Subsequently, DMEM without phenol red supplemented with FBS was added to the MTS solution in a 5:1 ratio and added to each well. The samples were incubated in the dark $\left(2 \mathrm{~h}\right.$ at $\left.37^{\circ} \mathrm{C}\right)$, and four replicate absorbance measurements were carried out. The results are shown as cell viability. The percentage of the cell viability of each sample was calculated according to eq 4 using the absorbance of PVDF at $24 \mathrm{~h}$ instead of the absorbance of the negative control.

2.8. Immunofluorescence. Immunofluorescence studies were carried out after 24 and $72 \mathrm{~h}$ of $\mathrm{C} 2 \mathrm{C} 12$ cell proliferation on the different samples. For that, the samples were washed with PBS solution three times, and the cells were fixed with $4 \%$ formaldehyde (Panreac) for $10 \mathrm{~min}$ at $37{ }^{\circ} \mathrm{C}$ in $95 \%$ humidified air containing 5\% $\mathrm{CO}_{2}$. Then, the samples were washed with PBS solution three times and incubated in a $1 \mu \mathrm{g} \mathrm{mL} \mathrm{m}^{-1}$ FITC-phalloidin (Sigma-Aldrich) solution for $45 \mathrm{~min}$ at room temperature. The samples were washed again with PBS solution and incubated in $0.1 \mu \mathrm{g} \mathrm{mL}^{-1} 4,6$-diamidino2-phenylindole (DAPI Sigma-Aldrich) solution for $5 \mathrm{~min}$. Finally, the samples were washed with PBS and observed with fluorescence microscopy (Olympus BX51 Microscope).

2.9. Statistical Analysis. The statistical analysis was analyzed using GraphPad Prism (v6.00, La Jolla, CA, USA). The results were analyzed using the two-way ANOVA test. Differences were considered to be significant when $p<0.05$.

\section{RESULTS AND DISCUSSION}

3.1. Morphological Characterization and Water Contact Angle. The morphology of the IL/PVDF composite samples was analyzed by SEM, and the images corresponding 
to pristine PVDF and the composite films with IL contents of 10, 20, and $40 \%$ wt. are shown in Figure 1.

Figure 1 shows that the spherulitic characteristic structure of this polymer remains the same after the IL incorporation and that, for the different composites, the spherulitic size decreases with increasing IL content, as reported for related composites. $^{12}$ Thus, the IL acts as a nucleating agent, leading to a large number of crystallization nuclei, and consequently, smaller spherulites are formed. Additionally, for high nuclei density, the spherulites are very close to each other and are characterized by well-defined borders, an effect that became more evident for IL contents from 10 to $40 \%$ wt. (Figure 1d). This effect is more evident for the $[\mathrm{Bmim}][\mathrm{Cl}] / \mathrm{PVDF}$ composites. For the $[\mathrm{Ch}][\mathrm{DHP}] / \mathrm{PVDF}$ composites, upon the incorporation of $20 \%$ wt. (Figure 1f), a lower porosity is observed, indicating that probably the IL occupies the space left by the DMF upon the DMF solvent evaporation.

Contact angle measurements (Figure S2, Supporting Information) show that the addition of both $[\mathrm{Bmim}][\mathrm{Cl}]$ and $[\mathrm{Ch}][\mathrm{DHP}]$ to PVDF leads to the increase of the wettability, as a result of the hygroscopic nature of the ILs and the polymer-IL interactions, leading to a decrease of the cation-anion interactions and consequently to higher surface tension of the composites. ${ }^{24,25}$ Interestingly, the highest reduction in contact angle is observed for the samples with the lower content of $[\mathrm{Bmim}][\mathrm{Cl}]$ and $[\mathrm{Ch}][\mathrm{DHP}]$, with the contact angle decreasing from 85 to $70 \pm 2.0^{\circ}$ and $65 \pm 2.6^{\circ}$, respectively. Increasing IL content leads to a slight increase of the contact angle of the $[\mathrm{Bmim}][\mathrm{Cl}] / \mathrm{PVDF}$ and $[\mathrm{Ch}]$ [DHP]/PVDF films.

3.2. Polymer Phase Content. FTIR-ATR allows the crystallization phase of PVDF to be assessede, as the incorporation of the IL may favor the presence of the electroactive phase. Figure 2 presents the FTIR-ATR spectra of the composites, and their main characteristic absorption bands are summarized in Table S2, Supporting Information.

It is observed that the inclusion of the different ILs in PVDF leads to differences with respect to the crystalline phase present in the polymer. The main absorption band characteristics of the $\alpha$-phase $\left(615,763\right.$, and $\left.796 \mathrm{~cm}^{-1}\right)$ and $\beta$-phase $\left(840 \mathrm{~cm}^{-1}\right)^{26,27}$ are observed in the spectra of both IL/PVDF composites. However, it is noticed that for higher IL contents, the $\alpha$-phase characteristic absorption bands decrease, and those attributed to the $\beta$-phase increase with the introduction of $[\mathrm{Bmim}][\mathrm{Cl}]$, whereas the phase content remains nearly unaltered with the introduction of $[\mathrm{Ch}][\mathrm{DHP}]$, up to the largest filler content. For the $[\mathrm{Bmim}][\mathrm{Cl}] / \mathrm{PVDF}$ composites, the absorption band at $1275 \mathrm{~cm}^{-1}$, ascribed to the $\beta$-phase, increases with the increase of the IL content. It is also noticed that the absence of the absorption bands at 1232 and 813 $\mathrm{cm}^{-1}$ are characteristic of the $\gamma$-phase. ${ }^{8,28}$ Thus, the strong electrostatic interactions that occur between the PVDF and IL promotes the nucleation of the PVDF $\beta$-phase and, in this sense, the formation of smaller spherulites, comparatively to the $\alpha$-phase. ${ }^{29}$

The characteristic absorption bands of $[\mathrm{Bmim}][\mathrm{Cl}]$ at 840 (vibration + $\mathrm{C}-\mathrm{N}$ stretching), 1635 ( $\mathrm{C}=\mathrm{C}$ stretching), and $3385 \mathrm{~cm}^{-1}$ (quaternary amine) ${ }^{30}$ and $[\mathrm{Ch}][\mathrm{DHP}]$ at 950 (CCO stretching), $1479\left(\mathrm{CH}_{3}\right.$ vibration), and $1644 \mathrm{~cm}^{-1}$ $(\nu(\mathrm{O}-\mathrm{H}))^{31}$ are also detected. No additional absorption bands are identified on the composites, indicating that the polymer-IL interactions are electrostatic. ${ }^{12}$ The $\beta$-phase content of the composites is presented in Table 1.
Table 1. $\beta$-Phase Content, Melting Temperature $\left(T_{\text {melting }}\right)$, and Degree of Crystallinity $\left(\Delta X_{c}\right)$ of PVDF and IL/PVDF Composites

\begin{tabular}{lcccc}
\multicolumn{1}{c}{ sample } & \% IL wt. & $\begin{array}{c}\beta \text {-phase } \\
\pm 3(\%)\end{array}$ & $T_{\text {melting }}\left({ }^{\circ} \mathrm{C}\right)$ & $\begin{array}{c}\Delta X_{\mathrm{c}} \\
\pm 2(\%)\end{array}$ \\
\hline PVDF & 0 & 34 & 171 & 51 \\
{$[$ Bmim $][\mathrm{Cl}] /$ PVDF } & 10 & 75 & 168 & 50 \\
& 20 & 89 & 166 & 52 \\
& 40 & 89 & 162 & 58 \\
{$[\mathrm{Ch}][\mathrm{DHP}] / \mathrm{PVDF}$} & 10 & 32 & 170 & 52 \\
& 20 & 36 & 169 & 49 \\
& 40 & 52 & 171 & 54 \\
\hline
\end{tabular}

Previous studies have demonstrated that the incorporation of ILs in the PVDF matrix influences the crystallization kinetics. ${ }^{29,32}$ The high number of electrostatic interactions that occurs between the IL charges and the dipolar moments of the PVDF chains induces the crystallization of the polymer in the $\beta$-phase all-trans chain conformation. ${ }^{11,17}$ The nucleation of the $\beta$-phase has been also observed in PVDF composites with barium titanate particles, ${ }^{33}$ zeolites, ${ }^{10}$ and cobalt ferrites ${ }^{11,34}$ and depends on the particle size and surface charge.

As it is shown in Table 1 , the amount of $\beta$-crystalline phase increases with the IL content, being that the effect is very different for the different IL. Composites with $[\mathrm{Bmim}][\mathrm{Cl}]$ present higher percentages of $\beta$-phase, reaching almost $90 \%$ with $20 \%$ wt. IL content. Nevertheless, even the higher concentration of $[\mathrm{Ch}][\mathrm{DHP}]$ leads to a lower $\beta$-crystalline fraction with the introduction of the lowest amount of $[\mathrm{Bmim}][\mathrm{Cl}]$ (Table 1$)$. These results indicate that the $[\mathrm{Bmim}][\mathrm{Cl}] / \mathrm{PVDF}$ polymer chain interaction between the cation with the $\mathrm{CH}_{2}$ groups and the anion with the $\mathrm{CF}_{2}$ groups of PVDF during the PVDF crystallization is more effective in inducing the PVDF all-trans (TTT) planar zigzag $\beta$-phase conformation. ${ }^{35}$

The highest $\beta$-phase values observed for the composites containing the $[\mathrm{Bmim}][\mathrm{Cl}] \mathrm{IL}$, comparatively to $[\mathrm{Ch}][\mathrm{DHP}] /$ PVDF composites, are attributed to cation-anion interactions and size. The higher cation size of [Bmim] leads to a decrease in the cation-anion interactions, as a result of the large cation surface area, favoring the IL-polymer interactions. ${ }^{35}$ Further, besides the anion [CHDP] incorporating into its chemical structure highly electronegative oxygen atoms (3.5), when compared to the chlorine atom (3.0), the higher anion size promotes a stereochemical hindrance for the interaction with the $\mathrm{CH}_{2}$ groups of PVDF.

3.3. Thermal Characterization. A DSC study was carried out to evaluate the influence of the IL incorporation on the melting temperature and the degree of crystallinity of the IL/ PVDF composites. Figure 3a,b shows the DSC scans for pristine PVDF and IL/PVDF composites with different IL contents.

For all samples, a single endothermic peak between 150 and $170{ }^{\circ} \mathrm{C}$, indicative of the polymer melting, is observed. ${ }^{20,36}$ No significant differences are observed in the melting temperatures of $[\mathrm{Ch}][\mathrm{DHP}] / \mathrm{PVDF}$ composites with increasing IL content. However, for the $[\mathrm{Bmim}][\mathrm{Cl}] / \mathrm{PVDF}$ composites, a slight decrease in melting temperature with the IL content increase is observed, indicating a destabilization of the crystalline phase as a result of the higher $[\mathrm{Bmim}]\left[\mathrm{FeCl}_{4}\right]-$ PVDF interactions as mentioned before (Figure 3 and Table 

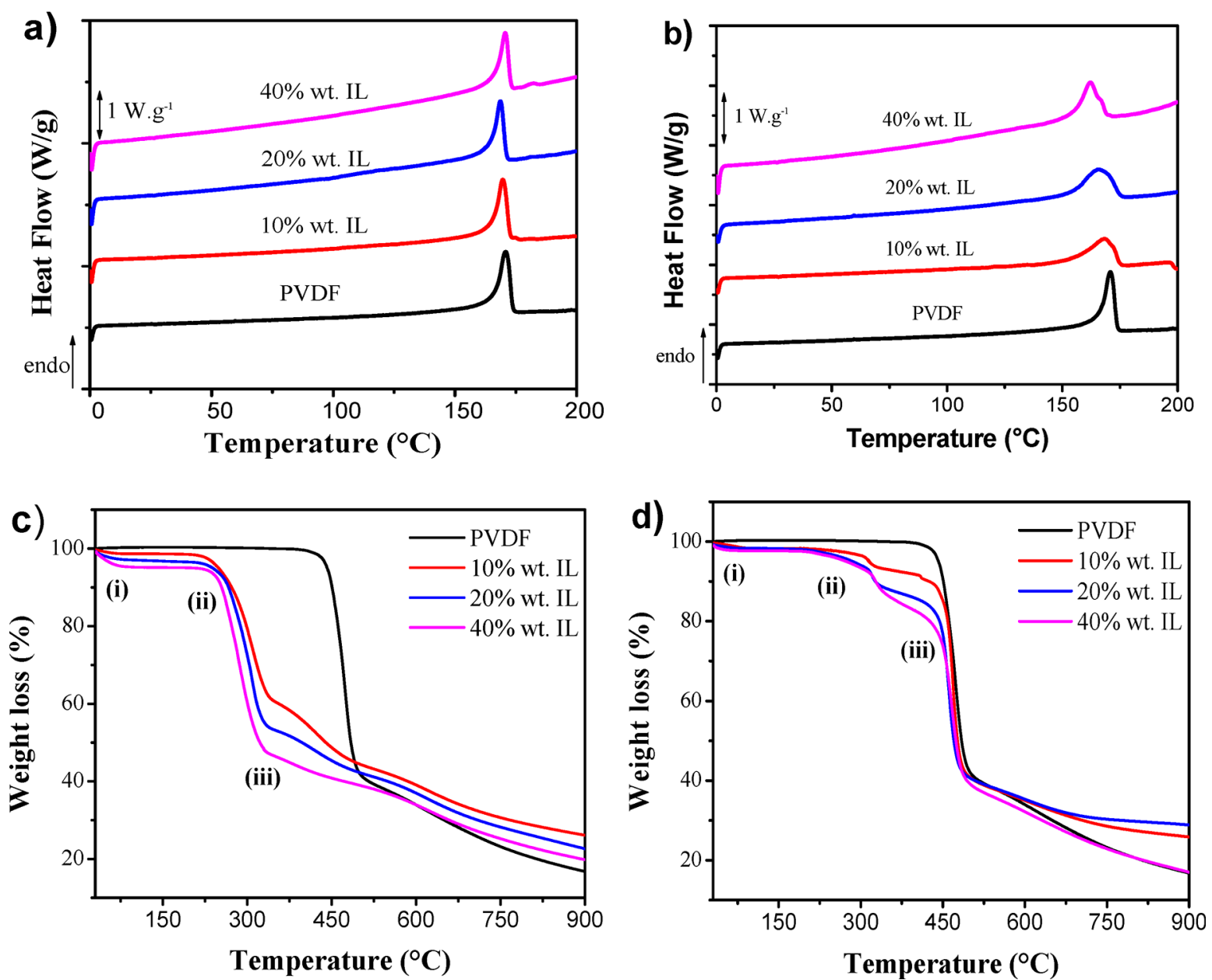

Figure 3. DSC thermograms for PVDF and the different IL/PVDF composites (a) [Ch][DHP]/PVDF and (b) [Bmim] [Cl]/PVDF, with 10, 20, and $40 \%$ wt. IL content; thermogravimetric curves obtained for neat PVDF and for composites (c) [Bmim] [Cl]/PVDF and (d) [Ch] [DHP]/ PVDF with 10, 20, and $40 \%$ wt. IL content. Both analyses were performed at a heating rate of $10{ }^{\circ} \mathrm{C} \mathrm{min}^{-1}$.
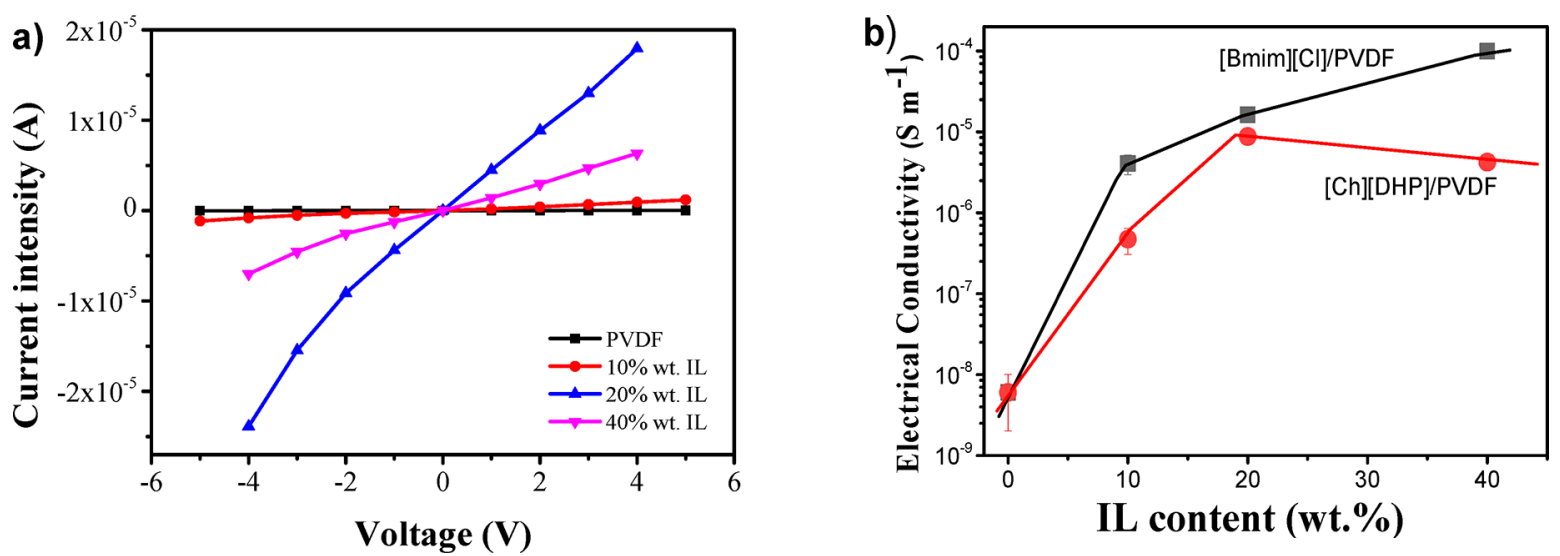

Figure 4. (a) Current-voltage intensity $(I-V)$ curves obtained for $[\mathrm{Ch}][\mathrm{DHP}] / \mathrm{PVDF}$ with different IL contents (10, 20, and 40\% wt.), and (b) electrical conductivity curves for neat PVDF and for $[\mathrm{Bmim}][\mathrm{Cl}] / \mathrm{PVDF}$ and $[\mathrm{Ch}][\mathrm{DHP}] / \mathrm{PVDF}$ with 10,20 , and $40 \%$ wt. IL content.

1). Regardless of the IL used, the degree of crystallinity (Table 1) of the different IL/PVDF composites, slightly increases with the IL content, indicating that during the crystallization process the ILs act as a nucleating agent.

The thermal stability of the IL/PVDF composite films was evaluated by thermogravimetric analysis (Figure 3c,d). Only a single degradation step is observed for neat PVDF (onset temperature near to $450{ }^{\circ} \mathrm{C}$ ), corresponding to the carbon- fluoride and carbon-hydrogen scission. ${ }^{37}$ The emergence of fluorine radicals $\left(\mathrm{F}^{-}\right)$and protons $\left(\mathrm{H}^{+}\right)$promotes the formation of polyenic chains and hydrogen fluoride (HF). In turn, both IL composites present three degradation steps, bearing noticeable differences. For $[\mathrm{Bmim}][\mathrm{Cl}] / \mathrm{PVDF}$, the initial weight loss step (i) starting below $150{ }^{\circ} \mathrm{C}$ is associated with water evaporation and the degradation of impurities present in the sample. ${ }^{38}$ The second degradation step (ii) 

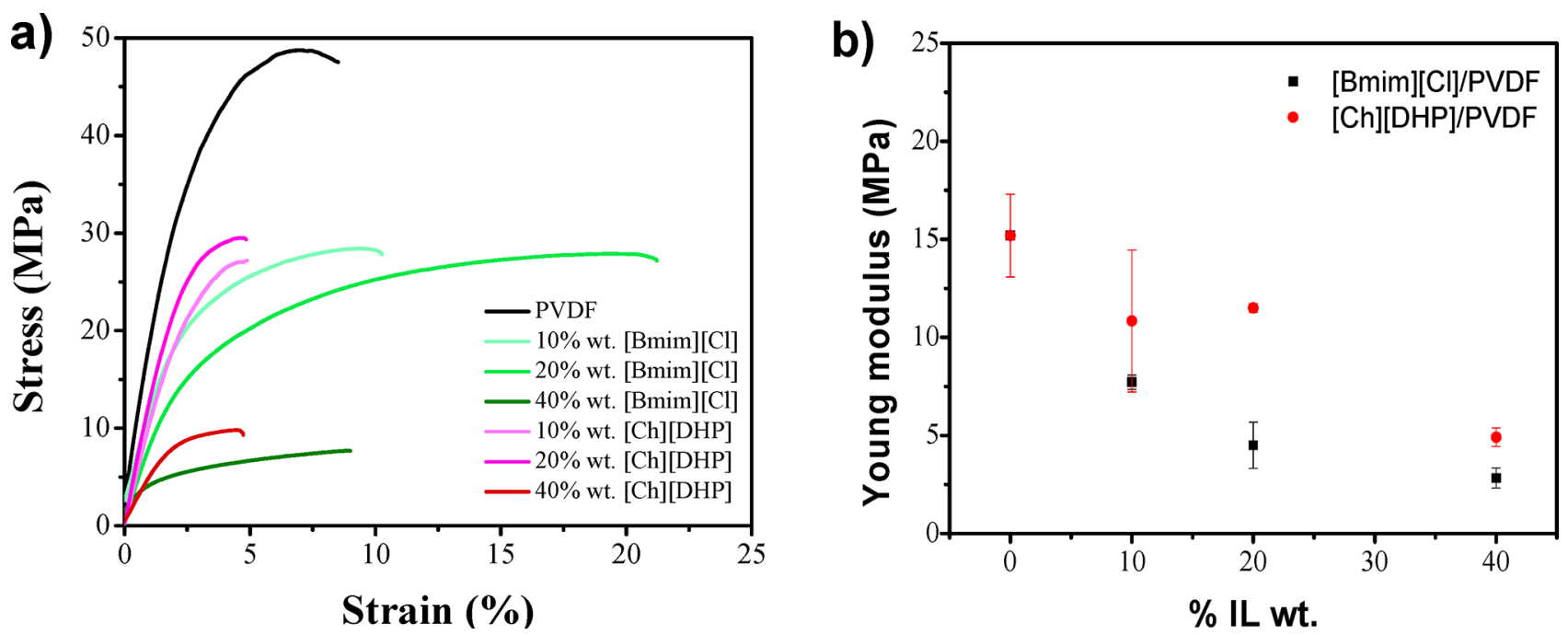

Figure 5. Stress-strain curves for (a) PVDF, $[\mathrm{Bmim}][\mathrm{Cl}] / \mathrm{PVDF}$, and $[\mathrm{Ch}][\mathrm{DHP}] / \mathrm{PVDF}$ with 10, 20, and 40\% w/w IL content. (b) Young moduli for the composites as a function of the IL content.

starts at $232{ }^{\circ} \mathrm{C}$ and is attributed to the decomposition of $[\mathrm{Bmim}][\mathrm{Cl}] .^{39}$ The third degradation step (iii), between 340 and $500{ }^{\circ} \mathrm{C}$, is related to the polymer degradation. ${ }^{37}$ Similarly, three steps are also observed for the composites containing $[\mathrm{Ch}][\mathrm{DHP}]$. The first weight loss step (i) is correlated with water evaporation. The second one (ii), around $320-330{ }^{\circ} \mathrm{C}$, is ascribed to the dehydration of the [DHP] anion. ${ }^{40}$ Finally, the third degradation step (iii), observed between 450 and $500{ }^{\circ} \mathrm{C}$, is similarly related to polymer degradation. ${ }^{37}$

As observed in Figure $3 \mathrm{c}$, the introduction of $[\mathrm{Bmim}][\mathrm{Cl}]$ decreases the thermal stability of the composites, because the onset temperature of the degradation process decreases with the increase of IL content, from 348 to $340{ }^{\circ} \mathrm{C}$. In contrast, the addition of IL $[\mathrm{Ch}][\mathrm{DHP}]$ increases the thermal stability, promoting a small increase in the temperature of degradation, from 447 to $454{ }^{\circ} \mathrm{C}$ (Figure 3d)..$^{40}$

3.4. Electrical Conductivity. The current-voltage intensity $(I-V)$ curves were obtained to evaluate the electrical conductivity of the samples. The $I-V$ curves of PVDF and $[\mathrm{Ch}][\mathrm{DHP}] / \mathrm{PVDF}$ composites with different IL contents are shown in Figure 4a.

The electrical conductivity (Figure 4b) was evaluated from the $I-V$ plots $([\mathrm{Ch}][\mathrm{DHP}] / \mathrm{PVDF}$, Figure $4 \mathrm{a}$, and $[\mathrm{Bmim}]$ $[\mathrm{Cl}] / \mathrm{PVDF}$, data not shown). Figure $4 \mathrm{~b}$ reveals that the introduction of IL into the PVDF matrix leads to an increase in the conductivity of the composites when compared to neat PVDF. ${ }^{12}$ The electrical conductivity increases with the $[\mathrm{Bmim}][\mathrm{Cl}]$ content from $4.06 \times 10^{-6}$ to $9.93 \times 10^{-5} \mathrm{~S}$ $\mathrm{m}^{-1}$. In the case of $[\mathrm{Ch}][\mathrm{DHP}]$ composites, the electrical conductivity slightly increases with the IL content up to $20 \%$ wt. of IL $\left(8.76 \times 10^{-6} \mathrm{~S} \mathrm{~m}^{-1}\right)$. This increase is attributed to the ionic charges of the IL (number and mobility) dispersed within the polymer matrix. ${ }^{41}$ As expected, slightly higher conductivity values are observed for the $[\mathrm{Bmim}][\mathrm{Cl}] / \mathrm{PVDF}$ composites as a result of the higher interactions between the $[\mathrm{Bmim}][\mathrm{Cl}]$ and PVDF comparatively to the $[\mathrm{Ch}][\mathrm{DHP}] /$ PVDF composites, corresponding to higher charge carriers mobility within the PVDF polymer matrix.

3.5. Mechanical Properties. The effect of the IL content on the mechanical response of the composites was analyzed through the stress-strain curves (Figure 5).
All samples revealed the typical behavior of a thermoplastic polymer characterized by a linear elastic region, yielding, and the inelastic region (Figure 5a), being independent of IL type and content. Further, it is also possible to observe that the yielding stress and strain is dependent on the IL type. As it can be observed, for both the composites, the yielding stress decreases with the increase of IL content, presenting the $[\mathrm{Bmim}][\mathrm{Cl}] / \mathrm{PVDF}$ the lowest yielding stress values but the highest yielding strains. The yielding stress decreases and the yielding strain increases with the IL content increase, being an indication of the plasticizing effect of the incorporation of the ILs within the polymer matrix.

The Young modulus was evaluated from the linear elastic regime (Figure $5 \mathrm{~b}$ ) showing that the incorporation of both ILs leads to a strong reduction of the elastic modulus, comparatively to the neat PVDF. The initial modulus decreases with the IL content increase, from 7.72 to 2.83 $\mathrm{MPa}$ in composites with [Bmim][Cl] and from 10.84 to 4.91 $\mathrm{MPa}$ in composites with $[\mathrm{Ch}][\mathrm{DHP}]$, indicating that the ILs act as a PVDF plasticizer within the polymer matrix. ${ }^{17}$

3.6. Electromechanical Properties. The electromechanical properties of the IL/PVDF films were also evaluated for the samples containing 10,20 , and $40 \%$ wt. by applying mechanical uniaxial strains, from 1 to $2.5 \%$ and 10 loadingunloading cycles (Figure 6). [Bmim][Cl]/PVDF composites were selected for these assays mainly because of their higher electrical conductivity.

The electromechanical response and repeatability cycles, linear resistance variation with mechanical deformation, and piezoresistive sensibility are presented in Figure 6.

Figure $6 \mathrm{a}, \mathrm{b}$ shows the electromechanical response of the films containing $10 \%[\mathrm{Bmim}][\mathrm{Cl}]$ with $1.5 \%$ deformation and $40 \%$ wt. $[\mathrm{Bmim}][\mathrm{Cl}]$ with $1 \%$ deformation, respectively. The electrical resistance decreases with increasing mechanical deformation and increases upon unloading the strain, which is related to ion mobility variations within the polymer matrix with the orientation of polymer chains during the deformation. Upon loading, stretching results in a more oriented polymeric chain structure, which facilitates ion mobility through the polymer matrix, and in this sense, the electrical conductivity increases as the applied strain varies from 1.0 to $2.5 \%$ (Figure $6 \mathrm{c}$ ). 

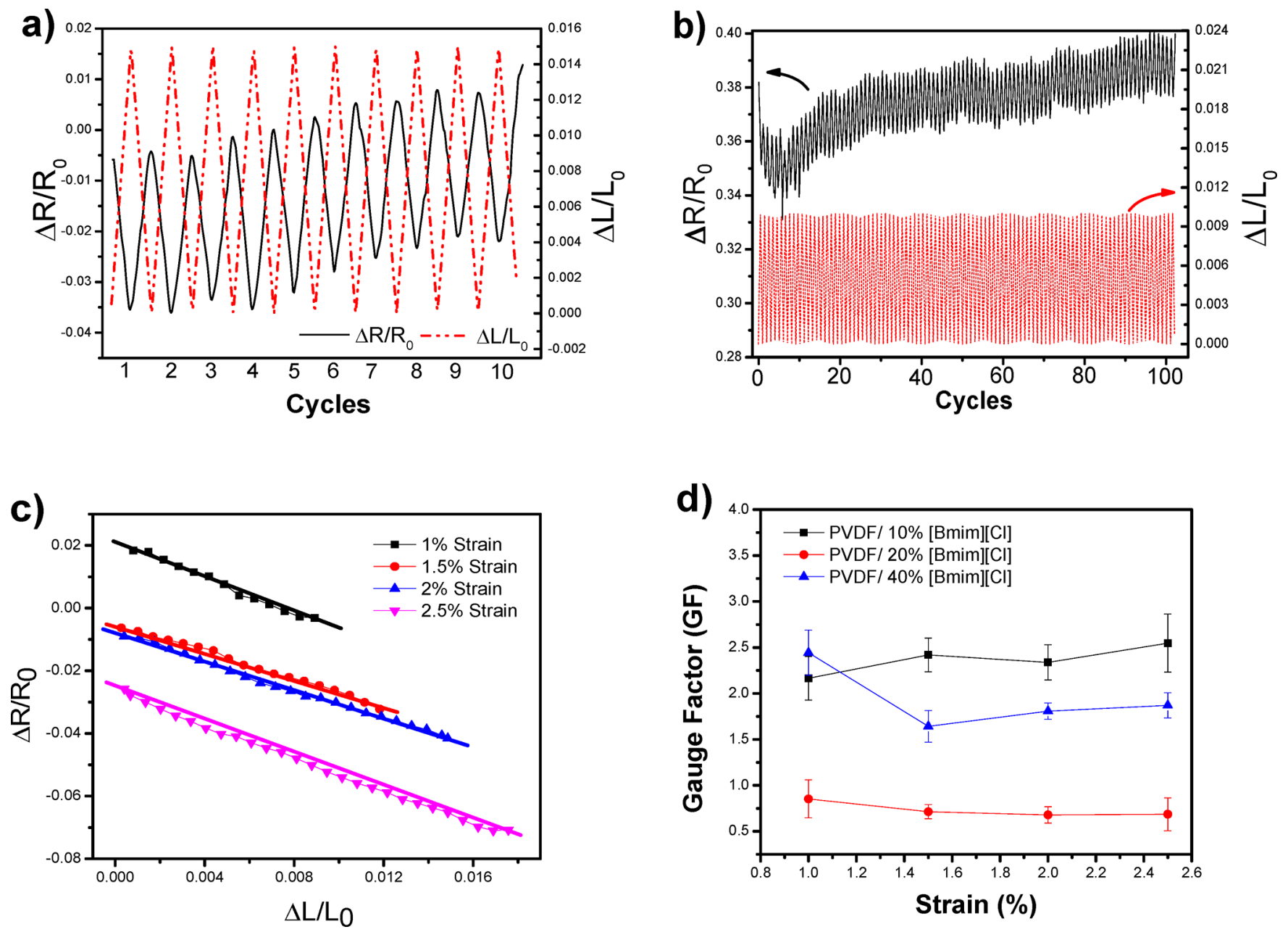

Figure 6. Representative piezoresistive measurements for (a) 10 cycles for $10 \% \mathrm{wt}$. [Bmim] [Cl] with $1.5 \%$ deformation and for (b) $100 \mathrm{cycles}$ for $40 \%$ wt. $[\mathrm{Bmim}][\mathrm{Cl}]$ with $1 \%$ deformation at $1.2 \mathrm{~mm} \mathrm{~min}^{-1}$; (c) strain and relative resistance variation as a function of the applied deformation and (d) gauge factor values of IL/PVDF composite materials, from 1 to $2.5 \%$ of strain.
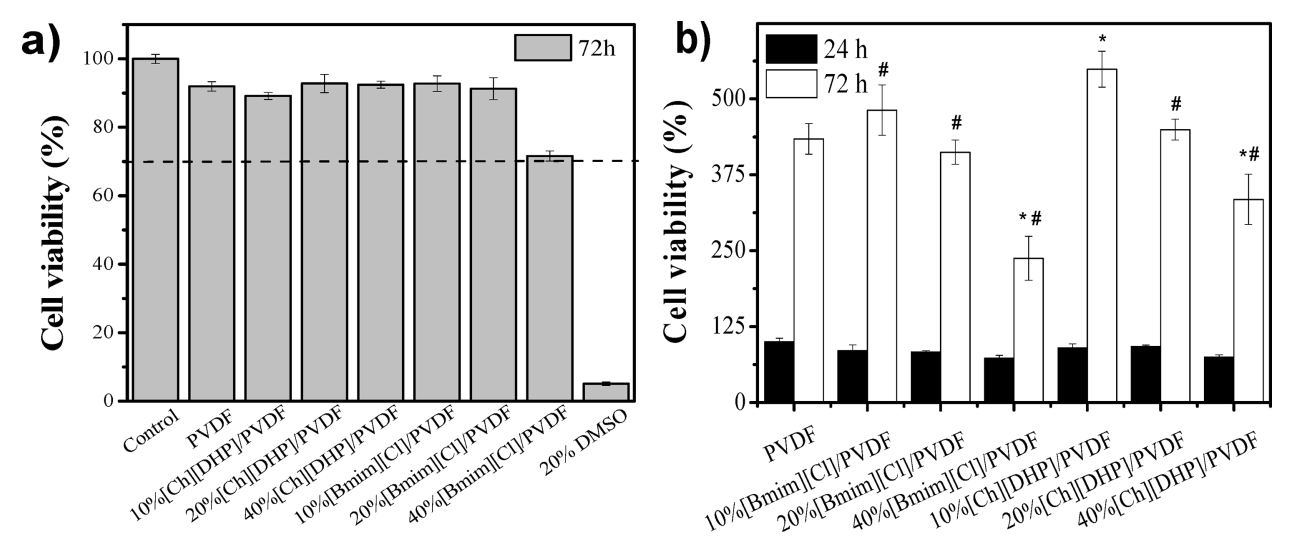

Figure 7. (a) Metabolic activity measured by an MTS assay of $\mathrm{C} 2 \mathrm{C} 12$ cells in contact with extraction media exposed to the IL/PVDF composites with different IL $[\mathrm{Bmim}][\mathrm{Cl}]$ and $[\mathrm{Ch}][\mathrm{DHP}]$ content. (b) Viability of cells grown on IL/PVDF composites with different IL types and content at 24 and $72 \mathrm{~h}$, measured using the MTS assay. The cell viability was calculated regarding the cells growing on the PVDF samples for $24 \mathrm{~h}$. Results are expressed as mean \pm standard deviation with $n=4{ }^{*} P<0.0001$ vs PVDF $72 \mathrm{~h}$ and $\# P<0.0001$ vs $10 \%[\mathrm{Ch}][\mathrm{DHP}] / \mathrm{PVDF} 72 \mathrm{~h}$.

Eq 3 was used to quantify the piezoresistive sensitivity of the composites. As observed, the GF slightly decreases with increasing IL content up to $40 \mathrm{wt} \%$ (Figure 6d). No significant differences in the samples containing 10 and $20 \%$ of IL are observed, with the GF independent of the applied strain. However, the incorporation of $40 \%$ wt. leads to a sensibility reduction from $\mathrm{GF} \approx 2.5$ to 1.5 . The electrical variation follows linearly the external mechanical stimulus for IL/PVDF from 10 to $40 \%$ wt., working as a strain sensor for low deformations, and allows the cells stimulation through the electromechanical stimulation. 
3.7. Cytotoxicity Assays. The eventual cytotoxicity of the extracts obtained from the IL/PVDF composite films was evaluated by an MTS assay method on a C2C12 myoblast cell line. The results are shown in Figure $7 \mathrm{a}$.

According to the ISO standard 109935-5, the samples are considered cytotoxic for cell viability values, as compared to the control, below 70\%. ${ }^{42}$ Thus, it is concluded that the composites are not cytotoxic for $\mathrm{C} 2 \mathrm{C} 12$ cells, although the composite with $40 \%$ wt. $[\mathrm{Bmim}][\mathrm{Cl}]$ content leads to a viability value near the limit. In this way, all the samples were subsequently used for cell proliferation assessment in direct contact experiments.

3.8. Cell Proliferation and Immunocytochemistry Assays. In order to study how the produced materials influence cell proliferation, direct contact assays were performed, and cell proliferation was monitored with the MTS assay after 24 and $72 \mathrm{~h}$ of contact. The results are represented in Figure $7 \mathrm{~b}$.

It is observed that the cell viability increased in all samples from 24 to $72 \mathrm{~h}$, with the increasing amount of IL impacting cell proliferation negatively. Moreover, comparing the two ILs, composites with $10 \%[\mathrm{Ch}][\mathrm{DHP}]$ present higher cell viability and proliferation. Because the samples were not in contact with the culture medium before being used in the cell culture assays, IL leaking from the material during the cell culture may be responsible for hindering cell proliferation.

The degrees of crystallinity and wettability are also important parameters for cell adhesion and proliferation. Because every composite presents a similar contact angle, the increment in cell proliferation may be due to the degree of crystallinity. Previous studies demonstrated that different crystallinities are associated with the sub-microenvironment variations that determined the different cell responses. ${ }^{42}$ Regarding the crystallinity of the composites (Table 1), it is observed that independently of the IL content, the crystallinity of the composites with $[\mathrm{Ch}][\mathrm{DHP}]$ is similar. Contrarily, the crystallinity of the composites with $[\mathrm{Bmim}][\mathrm{Cl}]$ increases with increasing of IL content, leading to a decrease of the cell proliferation. However, the difference between the crystallinity values does not seem very significant. In this way, the difference between the cell viability values of the different ILs content may be associated with the IL type and quantity. In relation to the composites with $[\mathrm{Bmim}][\mathrm{Cl}]$, the cell viability values are lower when compared with those of the composites with $[\mathrm{Ch}][\mathrm{DHP}]$, which can be attributed to a possible chemical reaction between the $\mathrm{Cl}^{-}$anion and the $\mathrm{H}^{+}$groups present in the culture medium, forming an acidic compound-hydrochloric acid $(\mathrm{HCl})$ (characterized as a weak acid).

Immunocytochemistry assays were also used to evaluate cell adhesion and morphology. Figure 8 shows that the cells adhered and proliferated in all samples, in agreement with the cell proliferation assays (Figure $7 \mathrm{~b}$ ). The myoblast cells are elongated and present a compact cytoskeleton particularly when growing on $[\mathrm{Bmim}][\mathrm{Cl}] / \mathrm{PVDF}$. $[\mathrm{Ch}][\mathrm{DHP}] / \mathrm{PVDF}$ promotes myoblasts with a more spread cytoskeleton and clearly visible membrane ruffles compatible with the existence of strong focal adhesions. Moreover, some well-defined orientation is present, which is also more evident with $[\mathrm{Ch}][\mathrm{DHP}] / \mathrm{PVDF}$. Thus, the IL composites seem to be a suitable platform for muscle TE, supporting cell adhesion and proliferation and allowing the possibility of electrical stimulation because of the conductivity of the films.

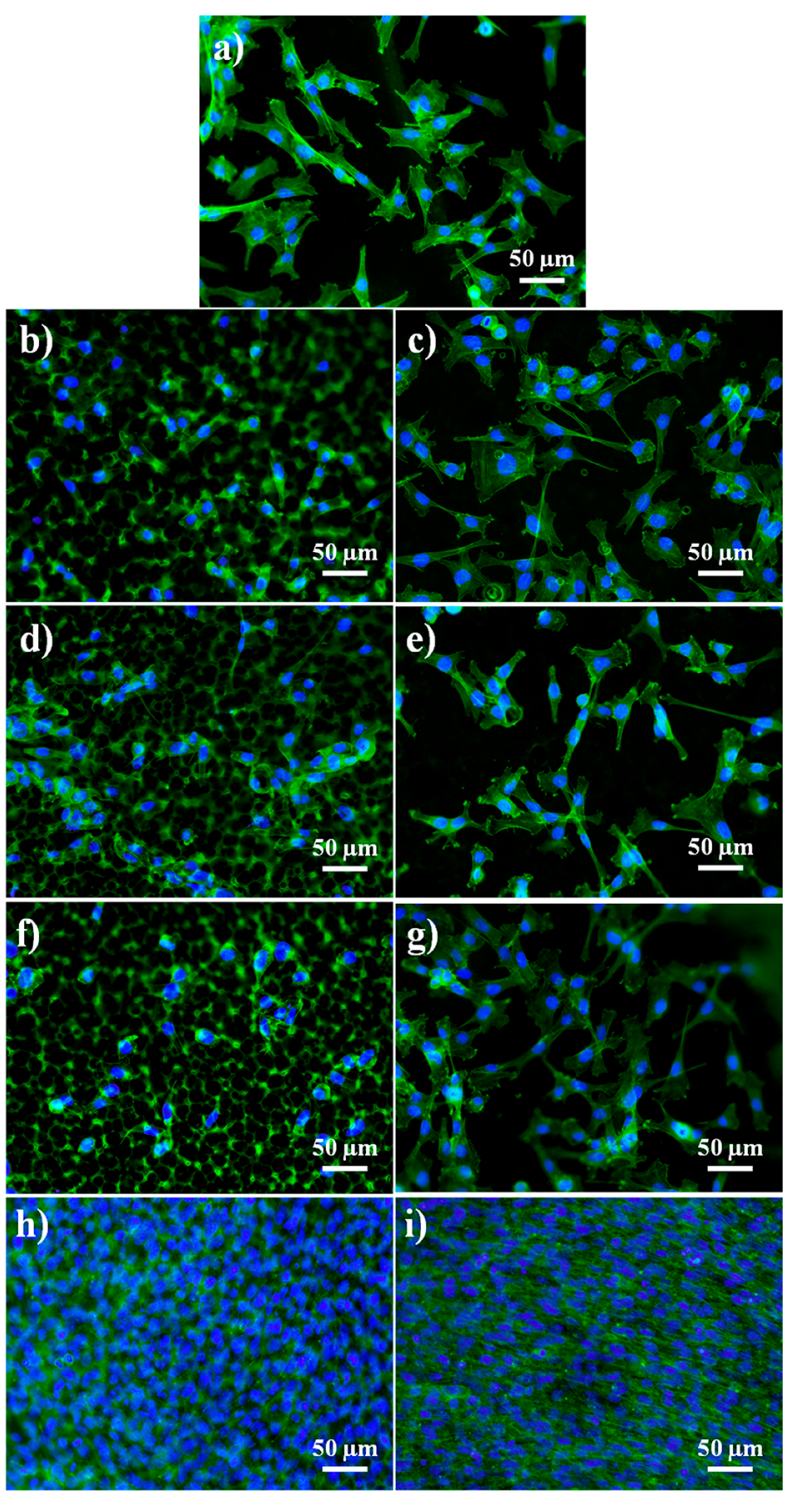

Figure 8. Immunocytochemistry assays in $\mathrm{C} 2 \mathrm{C} 12$ myoblast cells cultured in (a) pristine PVDF and composite films with (b) $10 \%$ wt. [Bmim] $[\mathrm{Cl}]$, (c) $10 \%$ wt. [Ch][DHP], (d) $20 \%$ wt. [Bmim] $[\mathrm{Cl}],(\mathrm{e})$ $20 \%$ wt. [Ch] [DHP], (f) $40 \%$ wt. $[\mathrm{Bmim}][\mathrm{Cl}]$, and (g) $40 \%$ wt. $[\mathrm{Ch}][\mathrm{DHP}]$ after $24 \mathrm{~h}$ of culture under static conditions. Composite films (h) $10 \%$ wt. [Bmim] $[\mathrm{Cl}]$ and (i) $10 \%$ wt. [Ch] [DHP] after 72 $\mathrm{h}$ of culture under static conditions as well. The myoblast nucleus was labeled with DAPI (blue), and the actin cytoskeleton was labeled with phalloidin-FITC (green).

\section{CONCLUSIONS}

IL/PVDF composites comprising different IL contents of $[\mathrm{Bmim}][\mathrm{Cl}]$ and $[\mathrm{Ch}][\mathrm{DHP}]$ were obtained by solvent casting for muscle tissue engineering applications. For all the composites, the incorporation of the ILs $[\mathrm{Bmim}][\mathrm{Cl}]$ and $[\mathrm{Ch}][\mathrm{DHP}]$ into the PVDF matrix promotes the PVDF crystallization into the $\beta$-phase, increasing the $\beta$-phase content with increasing IL content. The higher $\beta$-phase contents observed for the $[\mathrm{Ch}][\mathrm{DHP}] / \mathrm{PVDF}$ composites are attributed to cation-anion interactions and size. Further, also the degree of crystallinity increases with $[\mathrm{Bmim}][\mathrm{Cl}]$ and $[\mathrm{Ch}][\mathrm{DHP}]$ incorporation into the PVDF matrix. The thermal stability of the PVDF increases with the $[\mathrm{Ch}][\mathrm{DHP}]$ and decreases with the $[\mathrm{Bmim}][\mathrm{Cl}]$ incorporation. 
The introduction of IL in the polymer leads to an increase of the electrical conductivity, with a maximum conductivity of $9.93 \times 10^{-5} \mathrm{~S} \mathrm{~m}^{-1}$ for the $[\mathrm{Bmim}][\mathrm{Cl}] / \mathrm{PVDF}$ composites being observed. The incorporation of the ILs in PVDF also reveals a distinct behavior in the mechanical and electromechanical properties. For $[\mathrm{Bmim}][\mathrm{Cl}]$ composites, the maximum stress decreases with increasing IL content, boosting the maximum strain. For the $[\mathrm{Ch}][\mathrm{DHP}]$ composites, the maximum stress and strain decrease with any IL content. Piezoresistive measurements in $[\mathrm{Bmim}][\mathrm{Cl}]$ composites revealed that the variation of the electrical resistance follows linearly the mechanical deformation up to $2.5 \%$. The piezoresistive response shows a maximum GF of $\sim 2$ for composites with $40 \%$ wt. IL content.

All the IL/PVDF composites are not cytotoxic against $\mathrm{C} 2 \mathrm{C} 12$ cells, promoting the myoblast cell adhesion and proliferation, demonstrating that the composites are a suitable platform for active muscle regeneration strategies.

\section{ASSOCIATED CONTENT}

\section{(S) Supporting Information}

The Supporting Information is available free of charge on the ACS Publications website at DOI: 10.1021/acsapm.9b00566.

Table $S 1$ provides the chemical structure and main parameters of the used IL. Table S2 contains the characteristic absorption band assignments for pristine PVDF and IL/PVDF composite films. Figure $S 1$ is a representation of the technique used to produce the IL/ PVDF composite films. Figure S2 shows the wettability of the pristine PVDF and IL/PVDF composite films (PDF)

\section{AUTHOR INFORMATION}

\section{Corresponding Authors}

*E-mail: senentxu.lanceros@bcmaterials.net. (S.L.-M.)

*E-mail: dcorreia@utad.pt. (D.M.C.)

\section{ORCID}

D. M. Correia: 0000-0002-3118-4717

P. Costa: 0000-0001-9887-0925

C. Ribeiro: 0000-0002-9120-4847

\section{Author Contributions}

R.M.M. and D.M.C. contributed equally.

Notes

The authors declare no competing financial interest.

\section{ACKNOWLEDGMENTS}

This work was supported by the Portuguese Foundation for Science and Technology (FCT) in the framework of the Strategic Funding UID/FIS/04650/2019, UID/BIA/04050/ 2013 (POCI-01-0145-FEDER-007569) and UID/BIO/ $04469 / 2019$ unit and funded by national funds through Fundação para a Ciência e a Tecnologia (FCT) and by the ERDF through the COMPETE2020 - Programa Operacional Competitividade e Internacionalização (POCI) and projects POCI-01-0145-FEDER-028237 and POCI-01-0145-FEDER028159. The authors also thank the FCT for the SFRH/BD/ 148655/2019 (R.M.M.), SFRH/BPD/121526/2016 (D.M.C.) and SFRH/BD/111478/2015 (S.R.) grants. The authors acknowledge funding by the Spanish Ministry of Economy and Competitiveness (MINECO) through the project MAT2016-76039-C4-3-R (AEI/FEDER, UE) and from the
Basque Government Industry and Education Departments under the ELKARTEK, HAZITEK, and PIBA (PIBA-201806) programs, respectively.

\section{REFERENCES}

(1) Nerem, R. M.; Sambanis, A. Tissue Engineering: From Biology to Biological Substitutes. Tissue Eng. 1995, 1, 3-13.

(2) Chan, B. P.; Leong, K. W. Scaffolding in Tissue Engineering: General Approaches and Tissue-Specific Considerations. European Spine Journal 2008, 17, 467-479.

(3) O’Brien, F. J. Biomaterials \& Scaffolds for Tissue Engineering. Mater. Today 2011, 14, 88-95.

(4) Ribeiro, C.; Sencadas, V.; Correia, D. M.; Lanceros-Mendez, S. Piezoelectric Polymers as Biomaterials for Tissue Engineering Applications. Colloids Surf., B 2015, 136, 46-55.

(5) Qazi, T. H.; Mooney, D. J.; Pumberger, M.; Geißler, S.; Duda, G. N. Biomaterials Biomaterials Based Strategies for Skeletal Muscle Tissue Engineering: Existing Technologies and Future Trends. Biomaterials 2015, 53, 502-521.

(6) Martins, P. M.; Ribeiro, S.; Ribeiro, C.; Sencadas, V.; Gomes, A. C.; Gama, F. M.; Lanceros-Méndez, S. Effect of Poling State and Morphology of Piezoelectric Poly(Vinylidene Fluoride) Membranes for Skeletal Muscle Tissue Engineering. RSC Adv. 2013, 3, 1793817938 .

(7) Ribeiro, C.; Correia, D. M.; Ribeiro, S.; Sencadas, V.; Botelho, G.; Lanceros-Mendez, S. Piezoelectric Poly(Vinylidene Fluoride) Microstructure and Poling State in Active Tissue Engineering. Engineering in Life Sciences 2015, 15, 351-356.

(8) Martins, P.; Lopes, A. C.; Lanceros-mendez, S. Progress in Polymer Science Electroactive Phases of Poly (Vinylidene Fluoride): Determination, Processing and Applications. Prog. Polym. Sci. 2014, 39, 683-706.

(9) Ruan, L.; Yao, X.; Chang, Y.; Zhou, L.; Qin, G.; Zhang, X. Properties and Applications of the $\beta$ Phase Poly(Vinylidene Fluoride). Polymers 2018, 10, 228.

(10) Lopes, A. C.; Gonçalves, R.; Costa, C. M.; Fonseca, A. M.; Botelho, G.; Neves, I. C.; Lanceros-Mendez, S. Effect of Zeolite Content in the Electrical, Mechanical and Thermal Degradation Response of Poly(Vinylidene Fluoride)/Nay Zeolite Composites. J. Nanosci. Nanotechnol. 2012, 12, 6804-6810.

(11) Martins, P.; Costa, C. M.; Benelmekki, M.; Botelho, G.; Lanceros-Mendez, S. On the Origin of the Electroactive Poly(Vinylidene Fluoride) B-Phase Nucleation by Ferrite Nanoparticles Via Surface Electrostatic Interactions. CrystEngComm 2012, 14, 2807-2811.

(12) Mejri, R.; Dias, J.C.; Hentati, S. B.; Martins, M.S.; Costa, C.M.; Lanceros-Mendez, S. Effect of Anion Type in the Performance of Ionic Liquid/Poly(Vinylidene Fluoride) Electromechanical Actuators. J. Non-Cryst. Solids 2016, 453, 8-15.

(13) Xing, C.; Zhao, M.; Zhao, L.; You, J.; Cao, X.; Li, Y. Ionic Liquid Modified Poly(Vinylidene Fluoride): Crystalline Structures, Miscibility, and Physical Properties. Polym. Chem. 2013, 4, 57265734.

(14) Wang, J.; Luo, J.; Feng, S.; Li, H.; Wan, Y.; Zhang, X. Sciencedirect Recent Development of Ionic Liquid Membranes. Green Energy and Environment 2016, 1, 43-61.

(15) Gadilohar, B. L.; Shankarling, G. S. Choline Based Ionic Liquids and Their Applications in Organic Transformation. J. Mol. Liq. 2017, 227, 234-261.

(16) Thomas, E.; Parvathy, C.; Balachandran, N.; Bhuvaneswari, S.; Vijayalakshmi, K. P.; George, B. K. Pvdf-Ionic Liquid Modified Clay Nanocomposites: Phase Changes and Shish-Kebab Structure. Polymer 2017, 115, 70-76.

(17) Dias, J. C.; Lopes, A. C.; Magalhães, B.; Botelho, G.; Silva, M. M.; Esperança, J. M. S. S.; Lanceros-Mendez, S. High Performance Electromechanical Actuators Based on Ionic Liquid/Poly(Vinylidene Fluoride). Polym. Test. 2015, 48, 199-205. 
(18) Chinnappan, A.; Kim, H. Transition Metal Based Ionic Liquid (Bulk and Nanofiber Composites) Used as Catalyst for Reduction of Aromatic Nitro Compounds under Mild Conditions. RSC Adv. 2013, 3, 3399-3406.

(19) Li, Q.; Ardebili, H. Flexible Thin-Film Battery Based on SolidLike Ionic Liquid-Polymer Electrolyte. J. Power Sources 2016, 303, $17-21$.

(20) Dias, J. C.; Martins, M. S.; Ribeiro, S.; Silva, M. M.; Esperança, J. M. S. S.; Ribeiro, C.; Botelho, G.; Costa, C. M.; Lanceros-Mendez, S. Electromechanical Actuators Based on Poly(Vinylidene Fluoride) with [N1 $1112(\mathrm{Oh})][\mathrm{Ntf2}]$ and [C2mim] [C2so4]. J. Mater. Sci. 2016, 51, 9490-9503.

(21) Ribeiro, C.; Costa, C. M.; Correia, D. M.; Nunes-Pereira, J.; Oliveira, J.; Martins, P.; Goncalves, R.; Cardoso, V. F.; LancerosMendez, S. Electroactive Poly(Vinylidene Fluoride)-Based Structures for Advanced Applications. Nat. Protoc. 2018, 13, 681-704.

(22) Correia, D. M.; Gonçalves, R.; Ribeiro, C.; Sencadas, V.; Botelho, G.; Ribelles, J. L. G.; Lanceros-Méndez, S. Electrosprayed Poly(Vinylidene Fluoride) Microparticles for Tissue Engineering Applications. RSC Adv. 2014, 4, 33013-33013.

(23) Fernandes, L. C.; Correia, D. M.; García-Astrain, C.; Pereira, N.; Tariq, M.; Esperança, J. M. S. S.; Lanceros-Méndez, S. IonicLiquid-Based Printable Materials for Thermochromic and Thermoresistive Applications. ACS Appl. Mater. Interfaces 2019, 11, 2031620324.

(24) Yuan, Y.; Lee, T. R. Contact Angle and Wetting Properties. Surface Science Techniques 2013, 51, 3-34.

(25) Xing, C.; Guan, J.; Li, Y.; Li, J. Effect of a Room-Temperature Ionic Liquid on the Structure and Properties of Electrospun Poly(Vinylidene Fluoride) Nanofibers. ACS Appl. Mater. Interfaces 2014, 6, 4447-4457.

(26) Gregorio, R. Determination of the A, B, and $\Gamma$ Crystalline Phases of Poly(Vinylidene Fluoride) Films Prepared at Different Conditions. J. Appl. Polym. Sci. 2006, 100, 3272-3279.

(27) Cai, X.; Lei, T.; Sun, D.; Lin, L. A Critical Analysis of the A, B and $\Gamma$ Phases in Poly(Vinylidene Fluoride) Using Ftir. RSC Adv. 2017, 7, 15382-15389.

(28) Biswas, A.; Henkel, K.; Schmeißer, D.; Mandal, D. Comparison of the Thermal Stability of the A, B and $\Gamma$ Phases in Poly(Vinylidene Fluoride) Based on in Situ Thermal Fourier Transform Infrared Spectroscopy. Phase Transitions 2017, 90, 1205-1213.

(29) Mejri, R.; Dias, J. C.; Lopes, A. C.; Bebes Hentati, S.; Silva, M. M.; Botelho, G.; Mão De Ferro, A.; Esperança, J. M. S. S.; Maceiras, A.; Laza, J. M.; Vilas, J. L.; León, L. M.; Lanceros-Mendez, S. Effect of Ionic Liquid Anion and Cation on the Physico-Chemical Properties of Poly(Vinylidene Fluoride)/Ionic Liquid Blends. Eur. Polym. J. 2015, 71, 304-313.

(30) Dharaskar, S. A.; Varma, M. N.; Shende, D. Z.; Yoo, C. K.; Wasewar, K. L. Synthesis, Characterization and Application of 1Butyl-3 Methylimidazolium Chloride as Green Material for Extractive Desulfurization of Liquid Fuel. Scientific World Journal 2013, 2013, 395274.

(31) Du, C.; Zhao, B.; Chen, X.-B.; Birbilis, N.; Yang, H. Effect of Water Presence on Choline Chloride-2urea Ionic Liquid and Coating Platings from the Hydrated Ionic Liquid. Sci. Rep. 2016, 6, 29225.

(32) Zhu, Y.; Li, C.; Na, B.; Lv, R.; Chen, B.; Zhu, J. Polar Phase Formation and Competition in the Melt Crystallization of Poly (Vinylidene Fluoride) Containing an Ionic Liquid. Mater. Chem. Phys. 2014, 144, 194-198.

(33) Mendes, S. F.; Costa, C. M.; Caparros, C.; Sencadas, V.; Lanceros-Méndez, S. Effect of Filler Size and Concentration on the Structure and Properties of Poly(Vinylidene Fluoride)/Batio3 Nanocomposites. J. Mater. Sci. 2012, 47, 1378-1388.

(34) Sencadas, V.; Martins, P.; Pitães, A.; Benelmekki, M.; Gómez Ribelles, J. L.; Lanceros-Mendez, S. Influence of Ferrite Nanoparticle Type and Content on the Crystallization Kinetics and Electroactive Phase Nucleation of Poly(Vinylidene Fluoride). Langmuir 2011, 27, 7241-7249.
(35) Correia, D. M.; Barbosa, J. C.; Costa, C. M.; Reis, P. M.; Esperança, J. M. S. S.; de Zea Bermudez, V.; Lanceros-Méndez, S. Ionic Liquid Cation Size-Dependent Electromechanical Response of Ionic Liquid/Poly(Vinylidene Fluoride)-Based Soft Actuators. J. Phys. Chem. C 2019, 123, 12744-12752.

(36) Lopes, A. C.; Gutiérrez, J.; Barandiarán, J. M. Direct Fabrication of a 3d-Shape Film of Polyvinylidene Fluoride (Pvdf) in the Piezoelectric B-Phase for Sensor and Actuator Applications. Eur. Polym. J. 2018, 99, 111-116.

(37) Botelho, G.; Lanceros-Mendez, S.; Gonçalves, A. M.; Sencadas, V.; Rocha, J. G. Relationship between Processing Conditions, Defects and Thermal Degradation of Poly(Vinylidene Fluoride) in the BPhase. J. Non-Cryst. Solids 2008, 354, 72-78.

(38) Kamavaram, V.; Reddy, R. G. Thermal Stabilities of DiAlkylimidazolium Chloride Ionic Liquids. Int. J. Therm. Sci. 2008, 47, 773-777.

(39) Ismail, S.; Mansor, N.; Man, Z. A Study on Thermal Behaviour of Thermoplastic Starch Plasticized by [ Emim ] Ac and by [ Emim ] Cl. Procedia Eng. 2017, 184, 567-572.

(40) Rana, U. A.; Bayley, P. M.; Vijayaraghavan, R.; Howlett, P.; Macfarlane, D. R.; Forsyth, M. Proton Transport in Choline Dihydrogen Phosphate/H 3 Po 4 Mixtures. Phys. Chem. Chem. Phys. 2010, 12, 11291-11298.

(41) Leones, R.; Costa, C. M.; Machado, A. V.; Esperança, J. M. S. S.; Silva, M. M.; Lanceros-Méndez, S. Development of Solid Polymer Electrolytes Based on Poly(Vinylidene Fluoride-Trifluoroethylene) and the $\left[\begin{array}{lllll}\mathrm{N} 1 & 1 & 1 & 2(\mathrm{Oh})\end{array}\right][\mathrm{Ntf} 2]$ Ionic Liquid for Energy Storage Applications. Solid State Ionics 2013, 253, 143-150.

(42) Ribeiro, C.; Parssinen, J.; Sencadas, V.; Correia, V.; Miettinen, S.; Hytonen, V. P.; Lanceros-Mendez, S. Dynamic Piezoelectric Stimulation Enhances Osteogenic Differentiation of Human Adipose Stem Cells. J. Biomed. Mater. Res. 2015, 103, 2172-2175. 